DOI: 10.30519/ahtr. 528150

Advances in Hospitality and Tourism Research (AHTR)

\title{
WINNING THE BATTLE: THE IMPORTANCE OF PRICE AND ONLINE REVIEWS FOR HOTEL SELECTION
}

\author{
Olena CIFTCI ${ }^{1}$ \\ Department of Nutrition and Hospitality Management, The University of Mississippi, USA \\ ORCID: 0000-0003-2867-5897 \\ Katerina BEREZINA \\ Department of Nutrition and Hospitality Management, The University of Mississippi, USA \\ ORCID: 0000-0002-1309-9930
}

\section{Muhittin CAVUSOGLU}

School of Hotel and Restaurant Management, Northern Arizona University, USA ORCID: 0000-0003-2272-1004

\section{Cihan COBANOGLU}

College of Hospitality $\mathcal{E}$ Tourism Leadership, University of South Florida, USA ORCID: 0000-0001-9556-6223

\begin{abstract}
Traditionally, price has been one of the main revenue management levers that allow hotels to sell the right product to the right customer at the right time. Recent research in the area of electronic word-of-mouth has found that travelers' online reviews may also be an influential factor affecting other customers' booking decisions. However, it is challenging to determine the value of online reviews for customer decision making and to compare this value to hotel room prices. Therefore, the main goal of this study is to investigate which factors (room rate, online reviews' rating score, or the number of reviews by other travelers) are more important for customers' booking decisions and the optimal combination of these factors for booking a hotel. Conjoint analysis was applied to measure the relative importance of the aforementioned factors for travelers' booking decisions. The results revealed that the overall online rating was the most influential factor with regard to customer decision making about
\end{abstract}

Article History Received 17 February 2019 Revised 20 March 2020 Accepted 18 May 2020

\section{Keywords}

revenue management conjoint analysis user generated content review valence review volume eWOM

\footnotetext{
${ }^{1}$ Address correspondence to Olena Ciftci, Department of Nutrition and Hospitality Management, The University of Mississippi, USA. E-mail: ociftci@go.olemiss.edu
} 
booking a hotel. In addition, the following combination of factors was discovered to be optimal for attracting customer reservations: more than 107 reviews with an average rating of at least 3.3 (on a 5-point scale), and a price level of $\$ 130$ or below.

\section{INTRODUCTION}

Revenue management (RM) has been defined as "the application of information systems and pricing strategies to allocate the right capacity to the right customer at the right place at the right time" (Kimes, 2000, p.121). In the past, hoteliers often relied on two strategic RM levers, price and duration, to drive consumer response to their offerings. However, with the development of information systems and technology, consumers now have almost instant access to abundant travel information (e.g., product descriptions, prices and reviews) at their fingertips. In such a digitally accessible world, consumers may not react to hotel price and duration control as they did before because they have a multitude of options, easy algorithms to compare hotels and pricing, and other sources of information fighting for a share of consumer attention. In light of these changes in consumer behavior and access to information, hotels may find it challenging to determine the right strategies for attracting consumers, and the task of RM is becoming more complex than ever.

In this transition, user-generated content (UGC) on social media, and particularly online reviews, may be a valuable source of data and a communication tool for RM (Noone et al., 2011). According to a description of American travelers, 79\% reported consumer reviews on travel review websites as an influential factor when selecting accommodation (MMGY, 2019). This number is a $9.7 \%$ increase over the $72 \%$ of travelers who reported online reviews as influential in 2018. Given the growing importance of online reviews for selecting accommodation products, this research proposes to evaluate online reviews as one of the emerging levers of hotel RM.

When considering online reviews as one of the RM strategic levers, it is important to recognize that hotels have less control of online reviews compared to other RM levers such as duration and price. This paper does not propose fraudulent modification of a property's online reviews in an effort to increase attractiveness and financial performance of a subject hotel. It is, however, important to note that there are documented cases of this occurring in the hotel industry (Baka, 2016). This paper suggests using 
naturally occurring review metrics to support a hotel's RM practices and to possibly outperform or boost performance of other RM levers.

While it is unlikely that a hotel would impose duration restrictions based on its online review evaluations, the idea of manipulating the price based on favorable review recommendations has already been explored in the literature (Anderson, 2012; Noone \& McGuire, 2013a). The impact of online reviews and price on booking decision was broadly studied in the academic fields of hospitality and tourism (Blal \& Sturman, 2014; Book, Tanford, \& Chen, 2015; Book, Tanford, Montgomery, \& Love, 2015; Noone \& McGuire, 2013a, 2013b). In addition, researchers have tested the impact of the characteristics and features of online consumer reviews on the number of the hotel bookings (e. g. Anderson, 2012; Ayeh et al., 2013; Book, Tanford, Montgomery, \& Love, 2015; Mauri \& Minazzi, 2013; Sparks \& Browning, 2011) and the overall performance of hotels (e. g. Blal \& Sturman, 2014; Neirotti et al., 2016; Öğüt \& Taş, 2012; Torres et al., 2015).

In summary, online reviews have received considerable attention from hotel industry professionals and researchers. While acknowledging the overall importance of online reviews for hotel selection and purchase decision making, it is also crucial to note that online reviews come with a variety of attributes, and each of these attributes may be a factor driving consumer decisions. Despite the practical importance and extensive research conducted in the area of online hotel reviews, the value of the attributes of online hotel reviews, such as a rating score and number of reviews, for booking decisions is still unknown (Neirotti et al., 2016). Therefore, the purpose of this study is to explore the relative importance of hotel room rate and online review attributes (online hotel rating score and number of reviews) in terms of their ability to drive hotel reservations and, therefore, revenue for a hotel.

\section{LITERATURE REVIEW}

\section{User Generated Content in Hospitality Research}

The development of the Web 2.0 has resulted in significant growth in user generated content (UGC) or consumer generated content (CGC). UGC may be found in different forms, such as "product reviews, descriptions of product usage, "homemade advertising," blogs, and other consumerinitiated contributions" (Fader \& Winer, 2012, p. 369). Torres et al. (2013) separated various websites with UGC related to hospitality and tourism 
into three categories: social networking websites (i.e., Facebook, Twitter), online travel agencies (i.e., Expedia, Travelocity), and online feedback websites (i.e., Yelp, TripAdvisor). Similarly, Noone et al. (2011) suggested that "dominant sources of customer-generated content currently include user-generated content sites (for example, TripAdvisor and WikiTravel), reviews on online travel agent (OTA) sites (for example, Expedia), social networks and microblogging sites (for example, Facebook, Twitter) and media/video sharing sites (for example, YouTube)" (p. 296).

A study conducted by Fotis et al. (2012), in addition to others investigating UGC in hospitality (Anderson, 2012; Berezina et al., 2016; Book, Tanford, Montgomery, \& Love, 2015; Lu \& Stepchenkova, 2014; Mauri \& Minazzi, 2013), illustrates the exponential utilization of UGC on websites for making decisions on travel products and shaping images and perceptions on travel offers and destinations. UGC platforms enable travelers who use online interactions to search for the opinions of those consumers who are similar to themselves for travel advice (Ayeh et al., 2013). This has resulted in numerous hospitality and tourism businesses paying more attention to the use of UGC websites in their online business strategies (Ayeh et al., 2013).

Since UGC websites play an important role in many aspects of the travel industry, including improvement of service quality and guest satisfaction, they have exponentially become significant for industry practitioners (Anderson, 2012; Jeong \& Jeon, 2008; Wilson et al., 2012). However, UGCs have some problematic aspects. One of these may cause shifts in markets by changing or moving the purchasing pattern of consumers and affecting the performance of lodging businesses (Baka, 2016; Wilson et al., 2012).

\section{Word-of-Mouth and Electronic Word-of-Mouth in Hospitality}

When deciding whether or not to purchase a certain product or service, consumers often seek the opinions of others who have purchased those items previously. Such opinions may provide consumers with useful information regarding the experience with that particular service or product. This type of communication is commonly known as word-ofmouth (WOM) (Westbrook, 1987) and has been studied extensively.

Recently, researchers have been paying considerable attention to WOM communication, which is defined by Litvin et al. (2008) as "the 
communication between consumers about a product, service, or a company in which the sources are considered independent of commercial influence" (p. 459). Researchers have seen that purchasing decisions and customer engagement are considered to be highly influenced by WOM, and when such influence is positive, it may lead to increases in revenue generation (Baker et al., 2016; Litvin et al., 2008; Neirotti et al., 2016; Torres et al., 2015).

With the advancement and penetration of technology, such as the Internet and mobile devices, consumers are presented with opportunities to digitally engage in WOM communications. According to Litvin et al. (2008), today consumers have more ability and opportunities to post reviews of their experiences with the product online, which is called electronic word-of-mouth (eWOM). Being aware of its impact is extremely important. These online reviews are strong enough to affect future customers positively or negatively, and thus, boost or terminate consumers' connection to the brand, which will consequently impact the reputation of a firm in either way (Baka, 2016).

Furthermore, consumers generate eWOM by discussing and assessing the attributes of products to provide others with an overview of the subject product or service (Jalilvand et al., 2011). Thus, potential buyers may receive insights on a product or service before making the purchase by learning from previous customers (Baker et al., 2016). Buying decisions and search for information are traditionally influenced by WOM (Brown et al., 2007) and, by using the Internet, a greater number of consumers seem to willingly rely upon eWOM, which has become the key information source for certain services and products (Litvin et al., 2008). Therefore, it is now important to understand eWOM, especially for the service companies such as hotels (Sparks \& Browning, 2011).

eWOM communication has become a major component of consumers' marketing and decision making processes (Anderson, 2012; Fader \& Winer, 2012; Wilson et al., 2012). Moreover, UGC is perceived as more trustworthy when compared to official tourism websites, travel agents and mass media advertising (Fotis et al., 2012). Ultimately, eWOM reviews have a strong influence on consumer choices when purchasing products or services (Chu et al., 2018; Noone \& McGuire, 2013a, 2013b). Customers are no longer passive receivers of information from marketers, whether it is advertising or products featured on an e-commerce site. Instead, they interact with each other and the company, influencing consumer purchasing and decision making (Fader \& Winer, 2012). 
According to recent studies (Anderson, 2012; Blal \& Sturman, 2014; Öğüt \& Taş, 2012), eWOM affects overall hotel performance.

\section{Effect of Online Hotel Reviews on Booking Decisions}

Online consumer reviews are the most widely used form of UGC (Schuckert et al., 2015; Zhang et al., 2016). According to Gursoy et al. (2017), online review sites are one of the most important external information sources for both domestic and international travelers. Furthermore, the number of consumers that consult TripAdvisor reviews before they book a hotel room has continuously risen, along with the number of reviews that they read before they choose a hotel (Anderson, 2012).

A minimum of two components are included in online consumer reviews: the valence, which is the customer rating score of the product or service; and the volume, which is the number of discussions about the product or service (Blal \& Sturman, 2014; Cheung \& Thadani, 2012). Different combinations of these components impact a traveler's booking decision (Gursoy, 2019). Moreover, the effects of online hotel reviews on consumers' booking decisions also depend on other characteristics/features of online traveler reviews, such as usefulness, reviewer expertise, timeliness, and comprehensiveness (Zhao et al., 2015). In addition, Filieri and McLeay's research (2014) suggests that a consumer's likelihood of using information provided in online reviews in their decision-making process depends on the perceived quality, accuracy, and timeliness of these reviews. The complexity and ubiquitous nature of online consumer reviews make it difficult to understand the specific effect of the reviews on a traveler's decision-making process (Book, Tanford, Montgomery, \& Love, 2015) and on general hotel performance (Blal \& Sturman, 2014).

Recent studies provide meaningful insights into the effects of negative and positive reviews on hotel sales. Several studies have demonstrated the significant effect of negative reviews, particularly recent reviews, on evaluations before the purchase and booking intention (e.g., Lee et al., 2008; Ye et al., 2009; Zhao et al., 2015). However, such effects may lack symmetry (Book, Tanford, \& Chen, 2015). The negative online customer reviews, as one of the forms of social influence, cause customers to oppose their preexisting views and attitudes when they choose a resort holiday (Tanford \& Montgomery, 2015). A single negative review, which was written anonymously, does not necessarily impact travelers' judgments 
when all other reviews about the hotel are mostly positive (Book, Tanford, \& Chen, 2015).

Mauri and Minazzi (2013) and Leong et al. (2017) state that people tend to purchase more hotel products when the number of positive reviews is high, while Zhao et al. (2015) did not find any statistically significant effect between the valence of reviews and quantity of room sales. Park and Lee (2009) report that negative reviews have a greater effect on bookings than positive ones.

Studies confirm that rating scores have a positive effect on booking decisions: an increase in the review rating score leads to an increase in the likelihood of room sales (Mauri \& Minazzi, 2013; Öğüt \& Taş, 2012; Ye et al., 2011; Zhang et al., 2016). A study by Anderson (2012) illustrates that a $1 \%$ increase in a hotel's online rating score also leads to a $0.54 \%$ increase in a hotel's occupancy. Hu et al. (2014) find that online ratings impact sales indirectly via sentiments, and those sentiments affect sales significantly. However, Duverger (2013) reports a curvilinear relationship between the online ratings and market share; in other words, lodging properties with high online ratings would not necessarily see a benefit in market share.

Some research results reveal that the volume of online review content may be the predictor of consumers' purchasing decisions (Anderson, 2012; Blal \& Sturman, 2014; Gavilan et al., 2018; Torres et al., 2015). Zhao et al. (2015) illustrate the positive effects of the timeliness and volume of online reviews on booking intentions. However, Filieri and McLeay's (2014) study suggests that travelers do not pay attention to the number of online reviews during the decision-making process.

Furthermore, Anderson (2012) found that both the volume and valence of online reviews were positively correlated to the probability of online booking. A hotel with a higher overall TripAdvisor rating and a larger number of reviews has a higher average value per online booking transaction (Leong, et al., 2017; Torres et al., 2015). Torres et al. (2015) also state that simply increasing the number of reviews, regardless of whether they are positive or negative, increases the popularity of a hotel and drives its sales and profitability up. However, Blal and Sturman (2014) report that the impact of a number of online reviews on sales performance (including revenue per available room) is greater for lower-end hotels than for higherend hotels, and the review ratings have a more significant effect on luxury hotels than on lower-tier hotels. Moreover, the result of their study applies to franchised hotels, independent hotels, and properties operated by international chains (Blal \& Sturman, 2014). Viglia et al. (2016) found that 
"the number of reviews does count for hotels with a small number of reviews" (p. 2045).

\section{Effect of Hotel Room Rate and Online Hotel Reviews on Booking Decisions}

One of the important topics of investigation in the area of RM is the relationship between travelers' online review attributes and hotel key operating metrics, such as average daily rate (ADR), occupancy rate (OCC), revenue per available room (RevPAR) and, in particular, the effect of travel reviews and room rate interaction on likelihood to book (Noone et al., 2011).

Price is one of the primary factors influencing a travel purchase. However, online traveler reviews have also been counted as a major and powerful source shaping travel purchase intentions (Book, Tanford, Montgomery, \& Love, 2015). Price, brand name and online user-generated ratings have a significant effect on hotel choice. Of these, the ratings emerge as the strongest driver of choice (Noone \& McGuire, 2013a). Moreover, consumers integrate price information with non-price factors to appraise the product before the purchase, and consumers may shift to a higher price if a superior travel experience is suggested by the non-price information (Noone \& McGuire, 2013a). Furthermore, research demonstrates that, when online traveler reviews are available, price does not influence the perceived quality significantly, and price can be overridden by negative reviews (Noone \& McGuire, 2013b). However, Book, Tanford and Chen (2015) found that the impact of unanimous negative reviews was too strong to be offset by a price reduction offered at any level, but purchase decisions were influenced by a price reduction at an extreme level when the negative reviews were anonymous. Positive reviews were more subject to the price anchoring phenomenon, which was seen as the increasing willingness to pay at higher levels of price references (Book, Tanford, \& Chen, 2015; NietoGarcía et al., 2017).

Furthermore, studies by Öğüt and Taş (2012) and Anderson (2012) indicated a positive relationship between online customer ratings and room price. Moreover, the high-end hotels' prices appear to be more sensitive to online customer rating scores (Öğüt \& Taş, 2012). In addition, it was found that a hotel could increase the price for rooms and still maintain the same occupancy if it had a certain high level of online reputation (Anderson, 2012). An intriguing result from Anderson's research (2012) revealed that if a hotel's online rating score increased by 1 point on a 5-point scale, the hotel 
still maintained the same occupancy or market share after increasing its price by $11.2 \%$. In addition, it was found that increasing an online reputation score led to increases in RevPAR (Anderson, 2012; Blal \& Sturman, 2014; De Pelsmacker et al., 2018; Torres et al., 2015). Furthermore, the increasing importance of consumer generated online reviews is changing the character of hotel competition by focusing on volumes and higher room occupancy rates than on unit profit margin (Neirotti et al., 2016).

The joint impact of online hotel reviews and price on consumers' hotel booking intention has been a popular topic for academic investigation in the last two decades. This phenomenon has become particularly important for hospitality management with regard to developing pricing and marketing strategies (Book, Tanford, Montgomery, \& Love, 2015). Despite this practical importance and academic attention, the interrelationship between attributes of online hotel reviews and travelers' booking decisions remains unknown. To fill this gap, this research examines the following research question:

RQ1. What is the relative importance of a hotel room rate, an online review rating score, and the number of reviews for a traveler's decision to book a hotel?

\section{Conjoint Analysis}

Conjoint analysis can be useful in almost any academic or business investigation that measures consumers' perceptions or judgments and decision-making processes (Netzer et al., 2008). It can be employed for a wide variety of market research questions (Orme, 2010). Therefore, this analysis method has become a popular tool in hospitality research (Gregory, 2011; Lee, 2016).

Recent research in hospitality RM has demonstrated the use of conjoint analysis in predicting consumer preferences and managers' decision-making processes. Consumer preferences and segmenting markets were investigated based on room rates and rate fences (Guillet et al., 2015); and hotel attributes, such as room rate, star rating, location, brand, and room type (Wong et al., 2002). Lee (2016) employed choice-based conjoint $(\mathrm{CBC})$ analysis to understand the discount decision-making processes employed by hotel managers. This analysis was used to determine Chinese leisure travelers' preferences regarding rate fences 
(Guillet et al., 2013); and values of different hotel rate fences with the joint influence of room rates that customers perceived while booking a hotel room (Guillet et al., 2014). Using conjoint analysis, Millar and Baloglu (2011) studied the environmentally friendly attributes that guests prefer to have in a hotel room. A fixed-choice set conjoint analysis was employed by Repetti et al. (2015) to measure hotel customers' preferences for pricing strategies for hotel amenities in the form of a resort fee. In addition, Gregory (2011, 2013) used conjoint analysis to check consumer preference and willingness to pay for vacation ownership (timeshare) products. Moreover, CBC analysis was used to evaluate the optimal online travel agency commission fee (Van der Rest et al., 2016).

Although many studies in the hospitality RM area have used conjoint analysis to investigate customer preferences regarding a hotel room rate, there is no direct empirical evidence or formal study that employed a conjoint analysis to predict relative consumer preferences regarding price and attributes of online hotel reviews for hotel booking decisions.

\section{METHODS}

This study employed a CBC method to determine the most influential attribute among room rate, online travel review's rating score and a number of the reviews for making booking decisions, together with the value of each of these attributes for consumers' decision making. CBC is an appropriate technique in this situation as it allows measurement of customer preferences in a common unit (utility scores or part-worth) under the joint effect of other attributes (Orme, 2010). Thus, it makes this method useful for this particular research as previous academic literature indicated that price has a positive correlation with online rating score and number of reviews (Anderson, 2012; Öğüt and Taş, 2012). In this case, the CBC survey method simulated close to real-world trade-off situations in the marketplace. Respondents were presented with several hypothetical scenarios that included various combinations of attributes for a hotel selection (Orme, 2010). Participants could choose one combination of attributes among a few available in each of the scenarios, exactly like they would in a real life situation involving choosing a hotel for their trip (Gregory, 2013).

The attributes and levels examined in the current study are presented in Table 1. 
Table 1. Conjoint attributes and levels

\begin{tabular}{ll}
\hline Attributes & Levels \\
\hline & 1.8 \\
& 2.3 \\
& 2.8 \\
Online review rating score (out of 5.0) & 3.3 \\
& 3.8 \\
& 4.3 \\
& 4.8 \\
\hline & 4 \\
Number of reviews by other travelers & 24 \\
& 107 \\
& 256 \\
& 547 \\
& 1256 \\
& 2689 \\
\hline & $\$ 90$ \\
Price (per night) (\$) & $\$ 100$ \\
& $\$ 110$ \\
& $\$ 120$ \\
& $\$ 130$ \\
& $\$ 140$ \\
& $\$ 150$ \\
& $\$ 200$ \\
\hline
\end{tabular}

The average nightly price of a hotel room was determined at US $\$ 130$ based on the USADR of $\$ 129.83$ reported by STR for 2018 (HotelNewsNow, 2019). The low and high prices were considered as $\$ 90$ and $\$ 200$, respectively, with a $\$ 10$ spread of the price on either side of the average. The study did not use pricing specific to any particular market, but instead estimated low and high prices in relation to the national average. Such an approach did not require any specific market knowledge from the participants, but allowed respondents to rely on their travel experience in the US in general.

The number of online reviews was determined based on the previous literature. Gavilan et al. (2018) determined that, according to traveler perceptions, 102 represents a low number of reviews, and 913 represents a high number of reviews. The current study utilized an exponential distribution of 2 to produce different levels for the number of reviews. In these calculations, the authors tried to maintain equal representation of the numbers of reviews that fall on each interval suggested by the literature (below 102, between 102 and 913, and above 913). Since the exponential distribution of 2 contains several values under 102, the values were retained 
using the following logic. The lower boundary value was set at the second power of 2 (4). The upper boundary closest to 102 is the 7th power of 2, which is 128 . The upper value was modified to 107 to be closer to the value of 102 recommended in the literature. To select the values between the second and the seventh powers, the third power was skipped, the values of the fourth and the fifth powers were averaged to produce a value of 24 , and the sixth power was skipped. After the seventh power, the levels of the variable followed the exponential distribution of 2 closely, but the numbers were slightly manipulated to avoid resemblance of the selected exponential distribution and to create a more realistic look. The levels of this variable were stopped at the eleventh power, generating three values for the lower range, two values for the mid-range, and two values for the upper range of the numbers of reviews.

The levels of the online review rating score were determined based on the available literature and observation of these attributes on one of the most popular hotel online review websites, TripAdvisor. The extant research suggests that the distribution of hotel online reviews is negatively skewed with the majority of the ratings deviating towards the higher scores (Mariani \& Borghi, 2018; Racherla et al., 2013). In addition, it was noticed that TripAdvisor averages the scores to the closest half of a star. Using this information, the upper level of the online review rating was set at 4.8 to come close to the perfect score of 5 but avoiding it because the perfect score is hard to achieve and maintain. The following values were determined using a 0.5 leg $(4.3,3.8$, and so on), and stopped at 1.8 to reflect the trend of having more higher rated reviews. Overall, the chosen levels of the rating scores and the number of reviews were not extreme, as extreme levels may cause a reduction in believability (Hair et al., 2010).

A study of all possible attributes would require an analysis of 392 scenarios. To avoid frustrating the participants, the number of conjoint sets was reduced using a fractional factorial design (Orme, 2010) and QuestionPro's (online survey software) design functionality. QuestionPro randomly generated various versions of the $C B C$ scenarios from the orthogonal array with a level balance. Every respondent was presented with three independent scenarios that required them to choose a hotel room that they would like to book. Each of the scenarios contained two conjoint choices and one none alternative. The none option was employed to improve the reliability of the study results.

The questionnaire started with two screening questions that checked whether respondents had stayed in a hotel within the last 12 months and 
checked at least one online hotel review on a customer travel review website (such as TripAdvisor) before booking a hotel. The survey also contained questions about the travel and sociodemographic characteristics of the respondents. Then each participant was presented with CBC scenarios and asked to choose a room that they would book based on the available alternatives.

To improve the design and external validity of the study, the survey was pilot tested through social media with a sample of 40 individuals. The respondents were asked to indicate on a 7-point Likert scale (from 1 - not realistic at all to 7 - very realistic) the realism level of conjoint scenarios presented to them. The respondents found the conjoint choices highly realistic $(M=5.97, S D=1.221)$. Based on the feedback from the pilot test respondents, minor corrections were made to the survey instructions and content wording.

\section{Sample}

A survey of US hotel consumers who had stayed at a hotel within the previous 12 months and had checked a hotel review on consumer review websites (such as TripAdvisor) before booking a hotel was conducted. To ensure the accuracy of the study's conjoint instrument design, a sample size based on the formula of Johnson's rule-of-thumb recommended, by Orme (2010), was chosen:

$n^{*} t^{*} a / c>500$,

where " $\mathrm{n}$ is the number of respondents, $\mathrm{t}$ is the number of tasks, $\mathrm{a}$ is the number of alternatives per task (not including the none alternative)," and "c is the largest number of levels for any attribute" (pp. 64-65). Thus, for this research, a minimum sufficient sample size for producing valid conjoint results of aggregate-level full-profile CBC analysis is 667 respondents. To achieve the desired sample size, a higher number of surveys (total of 900) was collected from travelers with the help of the Amazon Mechanical Turk website. After the data evaluation and cleaning, 851 usable responses were retained for further analysis. According to Goodman et al. (2013), Mechanical Turk generates high-quality, reliable data. It also helps researchers to collect more diverse demographic of respondents than traditional methods. 


\section{Data Analysis}

In the current study, CBC analysis was used to measure customers' relative preferences for each level of three attributes: online review rating, number of online reviews and room rate. This analysis allows measurement of customer preferences in common units (utility scores or part-worth) under the joint effect of other attributes (Orme, 2010). Part-worth values were computed for each level of each attribute (Orme, 2010). Larger values corresponded to greater preferred levels (Orme, 2010). The attributes with the larger range of part-worth utilities were considered as more important in predicting preference than those with a smaller range of part-worth utilities (Orme, 2010). The hierarchical Bayes technique was used for estimation of individual-level part-worths and aggregated part-worths. Further, based on individual-level part-worths, the best and worst profiles of the attributes for a booking decision were found employing QuestionPro's conjoint simulator (Hair et al., 2010). In addition, market share simulations were performed to explore the value of one point of online review ratings. Descriptive statistics were used to analyze the data related to travel and sociodemographic characteristics of the respondents.

\section{RESULTS}

Almost equal number of males (54.27\%) and females (45.73\%) participated in the study. More than half the respondents were married, and $39.41 \%$ were single. The age of the majority of the respondents $(81.18 \%)$ was between 18 and 54 years; among them, 46.04\% were aged between 25 and 34. Approximately $38 \%$ of the respondents had a bachelor's degree, $28 \%$ had a master's degree or doctoral degree, and 25\% had a two-year college degree or some college education. Around one quarter $(26 \%)$ of the respondents earned an income of $\$ 25,000$ or less; all other respondents' household income distribution was relatively even. More than half of the respondents were born in the US (57.19\%), 25.45\% were born in India, 2.38\% in Turkey, and $1.19 \%$ in the UK; other countries were represented by $1 \%$ or less of the respondents. The demographic statistics for the respondents is presented in Table 2. 
Table 2. Respondents' demographic statistics

\begin{tabular}{|c|c|c|c|}
\hline Demographics & $\%$ & Demographics & $\%$ \\
\hline Gender & & Education & \\
\hline Male & 54.27 & Less than high school & 0.36 \\
\hline Female & 45.73 & High school/GED & 6.51 \\
\hline Age & & Some college & 17.87 \\
\hline Under 18 years & 0.00 & 2-year college degree & 7.81 \\
\hline 18 to 24 years & 12.54 & 4-year college degree & 38.58 \\
\hline 25 to 34 years & 46.04 & Master's degree & 24.02 \\
\hline 35 to 44 years & 22.60 & Doctoral degree & 4.14 \\
\hline 45 to 54 years & 11.12 & Professional degree (JD, & 0.71 \\
\hline 55 to 64 years & 6.63 & $\mathrm{MD})$ & \\
\hline 65 to 74 years & 0.95 & Household income & 26.04 \\
\hline 75 to 84 years & 0.12 & under $\$ 25,000$ & 11.95 \\
\hline 85 years or over & 0.00 & $\$ 25,000-\$ 29,999$ & 9.35 \\
\hline Marital status & & $\$ 30,000-\$ 34,999$ & 7.10 \\
\hline married & 52.66 & $\$ 35,000-\$ 39,999$ & 8.05 \\
\hline divorced & 4.62 & $\$ 40,000-\$ 49,999$ & 9.70 \\
\hline widowed & 1.30 & $\$ 50,000-\$ 59,999$ & 14.44 \\
\hline separated & 1.42 & $\$ 60,000-\$ 84,999$ & 13.37 \\
\hline single & 39.41 & Over $\$ 85,000$ & \\
\hline stepparent & 0.59 & & \\
\hline
\end{tabular}

The majority of the respondents (56.73\%) stayed in a hotel from 1-10 nights a year. A total of $68.14 \%$ stayed in a hotel less than three months before participating in the survey. More than $70 \%$ see themselves as savvy travelers. About $17 \%$ travel for business, while $47.86 \%$ travel for pleasure, and $35.26 \%$ travel for both. More than $39 \%$ of the respondents spend between $\$ 50$ and $\$ 100$, and $38.90 \%$ pay $\$ 101-\$ 150$ per night at a hotel. The majority of the respondents check online reviews about a hotel before booking most of the time $(30.38 \%$ ) or always $(29.80 \%)$. More than $80 \%$ of respondents indicated they trust other travelers' reviews about hotels.

\section{Conjoint Results}

The $\mathrm{CBC}$ analysis revealed that the most important attribute for respondents' booking decision is the online evaluation score $(49 \%$ of relative importance). Moreover, the positive influence on their decision had a rating over 3.3 out of five. The importance level of a room rate was found to be $29 \%$, making it the second most important factor for booking choice. A price higher than $\$ 130$ per night had negative effect on booking decision. 
The least influential attribute for booking the hotel among those included in the study was the number of online reviews ( $22 \%$ of relative importance). The number of the reviews greater than 107 had a positive impact on a hotel choice (see Table 3).

Table 3. Relative attribute importance and the levels' part-worths

\begin{tabular}{lccc}
\hline Attributes & $\begin{array}{c}\text { Relative } \\
\text { Importance }\end{array}$ & Levels & Part-worth \\
\hline & & 1.8 & -1.37 \\
& & 2.3 & -1.04 \\
Online review rating score & $49 \%$ & 2.8 & -0.64 \\
(out of 5.0) & 3.3 & 0.08 \\
& & 3.8 & 0.54 \\
& 4.3 & 1.08 \\
& 4.8 & 1.35 \\
\hline & & 4 & -0.82 \\
Number of reviews by other & $22 \%$ & 24 & -0.30 \\
travelers & & 107 & -0.01 \\
& & 256 & 0.33 \\
& & 547 & 0.14 \\
& & 2689 & 0.30 \\
& & $\$ 90.36$ \\
\hline
\end{tabular}

Generated by the conjoint simulator, the best profile of hotel attributes for a booking decision included 1258 online reviews by other travelers, an online rating score of 4.8 out of 5.0, and a price of US $\$ 100$ per night (see Table 4). Conversely, the worst profile of attributes for a booking decision was a combination of four online reviews, an online rating score of 1.8 out of 5.0 , and a price US $\$ 200$ per night (see Table 4 ). 
Table 4. Best and worst profiles of the levels of attributes

\begin{tabular}{lcclcc}
\hline \multicolumn{1}{c}{ Best Profile } & & & \multicolumn{2}{c}{ Worst Profile } \\
\cline { 1 - 2 } \cline { 5 - 6 } $\begin{array}{l}\text { Online review rating score } \\
\text { (out of 5.0) }\end{array}$ & 4.8 & & $\begin{array}{l}\text { Online review rating score } \\
\text { (out of 5.0) }\end{array}$ & 1.8 \\
$\begin{array}{l}\text { Number of reviews by other } \\
\text { travelers }\end{array}$ & 1256 & & $\begin{array}{l}\text { Number of reviews by other } \\
\text { travelers }\end{array}$ & 4 \\
Price (per night) $(\$)$ & $\$ 100$ & & Price (per night) $(\$)$ & $\$ 200$ \\
\hline
\end{tabular}

The results of 168 market share simulations revealed that a one-point increase in the online rating, while price and number of reviews were fixed, increased market share percentage, particularly in the case of the best profile combination price $\$ 100$ and 1256 reviews. The market share of the hypothetical hotel (later hotel) with an online rating score of 2.8 out of 5.0 was greater than one with an online rating score of 1.8 out of 5.0 with an $11.90 \%$ difference (see Table 5). When one of the hotels had an online rating of 2.8 out of 5.0 and the other one had 3.8 out of 5.0 with the same room rate and number of online reviews, their market share was $32.63 \%$ and $67.37 \%$ respectively. The hotel with an online review rating of 3.8 out of 5.0 had $11.42 \%$ less of market share than a hotel with an online rating score of 4.8 out of 5.0 while keeping price and number of reviews constant (see Table 5). All market share simulations indicated a greater difference in market share between hypothetical hotels with an online rating of 2.8 and 3.8 than between those with a rating score of 1.8 and 2.8 or 3.8 and 4.8 .

Table 5. Market share simulation results for the best profile combination of price and number of online reviews

\begin{tabular}{ccccccc}
\hline Price & $\begin{array}{c}\text { Number } \\
\text { of Online } \\
\text { Reviews }\end{array}$ & $\begin{array}{c}\text { Online Rating } \\
\text { Score of } \\
\text { Concept 1 }\end{array}$ & $\begin{array}{c}\text { Online } \\
\text { Rating Score } \\
\text { of Concept 2 }\end{array}$ & $\begin{array}{c}\text { Market } \\
\text { Share of } \\
\text { Concept 1 }\end{array}$ & $\begin{array}{c}\text { Market } \\
\text { Share of } \\
\text { Concept 2 }\end{array}$ & $\begin{array}{c}\text { Difference } \\
\text { in Market } \\
\text { Share }\end{array}$ \\
\hline \$100 & $\mathbf{1 2 5 4}$ & 1.8 & 2.8 & $44.05 \%$ & $55.95 \%$ & $11.90 \%$ \\
& & 2.8 & 3.8 & $32.63 \%$ & $67.37 \%$ & $34.74 \%$ \\
& & 3.8 & 4.8 & $44.29 \%$ & $55.71 \%$ & $11.42 \%$ \\
\hline
\end{tabular}

Furthermore, the majority of respondents indicated that they were willing to pay more for a hotel if it had a one point higher online review evaluation score: $8.98 \%$ of respondents would pay US\$5 more, $21.98 \%$ would pay US $\$ 10$ more, $17.38 \%$ agreed to pay US\$30 more. Only $9.55 \%$ of the respondents would not pay more for a hotel with higher online rating score. 


\section{DISCUSSION}

\section{Conclusions}

This study examined three hotel attributes (price, number of online reviews and overall review rating) in terms of importance for customers' booking decisions. The results of the study indicate that the hotel room price is not the main factor for customer decision making. It is only the second attribute that customers take into consideration when choosing a hotel. The online hotel review rating is the most important attribute in the hotel selection. The number of reviews is less important than online rating and price, but still has a significant influence on a booking decision.

Furthermore, the findings suggest that optimal levels are at least 3.3 out of 5.0 for an online review, \$130 per night or lower, and more than 100 reviews. The best profile of the hotel attributes for a customer's booking decision included 1258 online reviews by other travelers, an online rating score of 4.8 out of 5.0 , and a price of US\$100 per night. The worst hotel profile described a property with a 1.8 average rating based on four reviews, and a room rate of $\$ 200$. It is interesting to note that while the worst hotel profile included most undesirable attributes that were included in the study (the lowest ranking and number of reviews, and the highest price), the best profile did not include all best attributes. The $\$ 100$ price was below the US market average; however, it was not the lowest possible price included in the study. Similarly, the number of reviews (1256) corresponds with the high number of reviews, according to Gavilan et al. (2018), but does not require it to go higher.

Furthermore, the results of market share simulations reveal that only a one-point change in the online review rating score might significantly change the hotel market share (see Table 5). The results appear to be the most impactful when the review score crosses the line from an undesirable category into a desirable one. The current study determined the turning point in online review ratings at 3.3 out of 5.0. When the simulation results remained below (1.8 and 2.8) or above (3.8 and 4.8) this value, the forecast market share change was approximately $11 \%$. However, when the simulation scenario crossed the 3.3 line, moving from 2.8 to 3.3, the results suggested a jump in acquired market share of $34 \%$.

The findings of this study are in line with previous research (Book, Tanford, Montgomery, \& Love, 2015; Noone \& McGuire, 2013a) that suggest online traveler reviews are a major and powerful source of hotel booking intentions and a more influential factor than the hotel price (Noone 
\& McGuire, 2013a, 2013b). These findings reflect the highest importance of the online review rating score among the three attributes as well as confirming the findings of earlier studies (Anderson, 2012; Öğ̈̈t \& Taş, 2012) that a hotel can increase the price for rooms and still maintain the same level of sales/occupancy if it has a certain high level of online reputation.

The optimal, best, and worst combinations of price, rating score, and number of online reviews found in this study should not be considered as thresholds, but rather as indicative levels, because the results were gained based on an experiment that included specific discrete combinations of three hotel attributes (see Table 1). Instead, researchers and practitioners should view the combinations of the hotel attributes presented in this study as reference points with a zone of tolerance; when implemented in practice, these points should be evaluated to reflect the specific characteristics of each hotel.

\section{Theoretical Contributions}

The fundamental theoretical contribution that distinguishes the current study from similar studies is that it provides the optimal combination of online review rating score (out of 5.0), number of reviews by other travelers, price per night $(\$)$, and the relative importance of each attribute for hotel room selection. Moreover, although other studies (Leong, et al., 2017; Mauri \& Minazzi, 2013; Öğüt \& Taş, 2012; Torres et al., 2015; Ye et al., 2011; Zhang et al., 2016; Zhao et al., 2015) mentioned the importance of the online review rating score, number of reviews and price, they could not sort these three attributes by their importance. The current study was able to accomplish this task by using experimental design and CBC analysis.

Another contribution of this research is that it utilized a CBC method for defining relative importance of price and online review attributes. This method is found to be very effective in predicting the preferences and relative importance of the studied variables for the customers (Orme, 2010). Furthermore, "attributes whose impacts are immediate and concrete come to the fore compared to those that are distant or abstract [rating or ranking tasks]" (Huber, 1997, p. 8). In addition, CBC is a preferred method compared to other types of conjoint analysis (Orme, 2010). When choicebased questions are provided, it becomes more powerful than analysis of traditional full profile questions. While the full-profile conjoint analysis is characterized by simultaneous presentation of a large number of product 
profiles, the $\mathrm{CBC}$ survey method simulates close to real-world trade-off situations in the marketplace. Therefore, the $\mathrm{CBC}$ method is more aligned with customer behavior when choosing a hotel room. Since this study utilized the choice tasks as sets of products in a competitive context, it contributes to the current literature by providing better and reliable results.

\section{Managerial Implications}

The results of this study suggest that online reviews may be considered and used as one of the strategic levers of RM. Since online review attributes were investigated in relation to hotel price in this study, three key conclusions may be made. First, if a hotel does not reach a certain desired level of online review ratings, it may lose the opportunity to compete on price. The relative importance of the studied attributes, as well as the simulation results, substantiate this conclusion. Second, hotels may earn a higher market share when their average review score increases. Third, hotels may integrate online review score as a factor in their pricing decisions.

The study provides the following suggestions for hospitality managers. Traditionally, hotels have built their pricing strategies on "forecasted levels of demand, the price elasticity of demand, or competitors' prices" (Nieto-García et al., 2017, p. 73). However, this study's findings, as is the case for many other studies (e.g. Book, Tanford, Montgomery, \& Love, 2015; Nieto-García et al., 2017; Noone \& McGuire, 2013a, 2013b), suggest that online reviews play an important role in customers' hotel booking decisions and should be taken into consideration in hotel pricing strategies. First, hotel operators should adjust their dynamic pricing practices depending on the online review rating score as, according to this study's results, the rating score is more important than price and number of reviews for travelers' hotel booking decisions. In addition, managers should always bear in mind that every additional one point of online rating score may increase their market share significantly.

The number of online reviews was found to be the least important attribute in comparison with online review rating score and price. However, this does not suggest that managers should not make an effort to increase the volume of the guest reviews in social media. The overall online review rating score can be increased by increasing the number of positive reviews. Therefore, hotel managers should encourage satisfied guests to leave feedback about their hotel on social media. Thus, their online rating will increase, allowing the hotel to raise prices. 
In addition, the optimal combination of factors introduced in this study may help hotel managers to maintain a balance between attributes of travelers' online reviews and price and indicate the potential reason for an increase/decrease in bookings. These results may be used by the hotel groups, which includes all classifications of hotel, and serve travelers who have different characteristics and come from different sociodemographic backgrounds to determine their current situation in the market.

\section{Limitations and Future Research}

Several points should be discussed as they could be limitations of this study. First, the average nightly price for a hotel room in the US was taken as an average for all types of hotels. However, this study did not take into consideration classifications of hotels (e.g. star ratings, level of services, size, target markets, and chain scales). If these classifications of hotel are added to the study, based on Johnson's rule-of-thumb, a significant number of respondents is required, which is not feasible to achieve due to time and resource constraints (Orme, 2010). However, future studies may consider evaluating the studied variables in narrower contexts.

Although gender was almost equally distributed in the sample, respondents were not equally distributed in terms of travel purpose, length of stay and their latest travel before participating in the survey. Therefore, comparisons based on sub-categories' demographic features (e.g. travel purpose and length of stay) could not be included in the study. Thus, this research demonstrated the aggregate importance structure for all types of hotels and all types of travelers. However, this one-size-fits-all targeting approach is another limitation of this study.

Future studies may include segmentation analysis to compare differences in classification of hotels, demographics and characteristics of travelers. In addition, a cluster analysis could be run after reporting aggregated results to discover the difference in the attributes' importance for different homogeneous groups of respondents. It may help revenue managers to understand the market and build price strategies based on results. Moreover, similar research may be conducted in different geographical destinations. Thus, the importance of the attributes may be observed regarding different segments and groups. 


\section{REFERENCES}

Anderson, C. (2012). The impact of social media on lodging performance. Cornell Hospitality Report, 12(15), 6-11.

Ayeh, J. K., Au, N., \& Law, R. (2013). “Do we believe in TripAdvisor?" Examining credibility perceptions and online travelers' attitude toward using user-generated content. Journal of Travel Research, 52(4), 437-452. https://doi.org/10.1177/0047287512475217

Baka, V. (2016). The becoming of user-generated reviews: Looking at the past to understand the future of managing reputation in the travel sector. Tourism Management, 53, 148-162. https://doi.org/10.1016/j.tourman.2015.09.004

Baker, A. M., Donthu, N., \& Kumar, V. (2016). Investigating how word-of-mouth conversations about brands influence purchase and retransmission intentions. Journal of Marketing Research, 53(2), 225-239. https://doi.org/10.1509/jmr.14.0099

Berezina, K., Bilgihan, A., Cobanoglu, C., \& Okumus, F. (2016). Understanding satisfied and dissatisfied hotel customers: text mining of online hotel reviews. Journal of Hospitality Marketing \& Management, 25(1), 1-24. https://doi.org/10.1080/19368623.2015.983631

Blal, I., \& Sturman, M. C. (2014). The differential effects of the quality and quantity of online reviews on hotel room sales. Cornell Hospitality Quarterly, 55(4), 365-375. https://doi.org/10.1177/1938965514533419

Book, L. A., Tanford, S., \& Chen, Y.-S. (2015). Understanding the impact of negative and positive traveler reviews social influence and price anchoring effects. Journal of Travel Research,55(8), 993-1007. https://doi.org/10.1177/0047287515606810

Book, L. A., Tanford, S., Montgomery, R., \& Love, C. (2015). Online traveler reviews as social influence price is no longer king. Journal of Hospitality $\mathcal{E}$ Tourism Research, 42(3), 445 - 475. https://doi.org/10.1177/1096348015597029

Brown, J., Broderick, A. J., \& Lee, N. (2007). Word of mouth communication within online communities: Conceptualizing the online social network. Journal of Interactive Marketing, 21(3), 2-20. https://doi.org/10.1002/dir.20082

Cheung, C. M. K., \& Thadani, D. R. (2012). The impact of electronic word-of-mouth communication: A literature analysis and integrative model. Decision Support Systems, 54(1), 461-470. https://doi.org/10.1016/j.dss.2012.06.008

Chu, S. C., Lien, C. H., \& Cao, Y. (2018). Electronic word-of-mouth (eWOM) on WeChat: Examining the influence of sense of belonging, need for self-enhancement, and consumer engagement on Chinese travellers' eWOM. International Journal of Advertising, 23(2), 1-24. https://doi.org/10.1080/02650487.2018.1470917

De Pelsmacker, P., van Tilburg, S., \& Holthof, C. (2018). Digital marketing strategies, online reviews and hotel performance. International Journal of Hospitality Management, 72, 47-55. https://doi.org/10.1016/j.ijhm.2018.01.003

Duverger, P. (2013). Curvilinear effects of user-generated content on hotels' market share a dynamic panel-data analysis. Journal of Travel Research, 52(4), 465-478. https://doi.org/10.1177/0047287513478498

Fader, P. S., \& Winer, R. S. (2012). Introduction to the special issue on the emergence and impact of user-generated content. Marketing Science, 31(3), 369-547. https://doi.org/10.1287/mksc.1120.0715

Filieri, R., \& McLeay, F. (2014). E-WOM and accommodation an analysis of the factors that influence travelers' adoption of information from online reviews. Journal of Travel Research, 53(1), 44-57. https://doi.org/10.1177/0047287513481274 
Fotis, J., Buhalis, D., \& Rossides, N. (2012). Social media use and impact during the holiday travel planning process. In P. M. Fuchs, P. F. Ricci, \& P. L. Cantoni (Eds.), Information and communication technologies in tourism 2012 (pp. 13-24). Vienna, Austria: Springer. Retrieved from http://link.springer.com/chapter/10.1007/978-37091-1142-0_2

Gavilan, D., Avello, M., \& Martinez-Navarro, G. (2018). The influence of online ratings and reviews on hotel booking consideration. Tourism Management, 66, 53-61. https://doi.org/10.1016/j.tourman.2017.10.018

Goodman, J. K., Cryder, C. E., \& Cheema, A. (2013). Data collection in a flat world: The strengths and weaknesses of Mechanical Turk samples. Journal of Behavioral Decision Making, 26(3), 213-224. https://doi.org/10.1002/bdm.1753

Gregory, A. M. (2011). Assessment of product and service attributes and consumers' willingness to pay in the vacation ownership industry using the Kano Model and conjoint analysis. Unpublished doctoral dissertation, University of Central Florida, Orlando, FL. Retrieved from https://stars.library.ucf.edu/etd/1931/

Gregory, A. M. (2013). Examining the impact of negative attributes on consumer preference and willingness to pay in the vacation ownership industry: A conjoint analysis. Journal of Tourism Research \& Hospitality, 2(3), 1-5. https://doi.org/10.4172/23248807.1000120

Guillet, B. D., Guo, Y., \& Law, R. (2015). Segmenting hotel customers based on rate fences through conjoint and cluster analysis. Journal of Travel \& Tourism Marketing, 32(7), 835-851. https://doi.org/10.1080/10548408.2015.1063825

Guillet, B. D., Law, R., \& Xiao, Q. (2013). Rate fences in hotel revenue management and their applications to Chinese leisure travelers a fractional factorial design approach. Cornell Hospitality Quarterly, 55(2), 186-196. https://doi.org/10.1177/1938965513507497

Guillet, B. D., Liu, W., \& Law, R. (2014). Can setting hotel rate restrictions help balance the interest of hotels and customers? International Journal of Contemporary Hospitality Management, 26(6), 948-973. https://doi.org/10.1108/IJCHM-01-2013-0020

Gursoy, D. (2019). A critical review of determinants of information search behavior and utilization of online reviews in decision making process (invited paper for 'luminaries' special issue of International Journal of Hospitality Management). International Journal of Hospitality Management, 76, 53-60.

Gursoy, D., Del Chiappa, G., \& Zhang, Y. (2017). Preferences regarding external information sources: A conjoint analysis of visitors to Sardinia, Italy. Journal of Travel \& Tourism Marketing, 34(6), 806-820.

Hair, J. F., Black, W. C., Babin, B. J., \& Anderson, R. E. (2010). Multivariate data analysis (7th ed.). Upper Saddle River, NJ: Pearson Prentice Hall.

HotelNewsNow. (2019). STR: US hotels post another record year in 2018. Retrieved June 04, 2020, from http://www.hotelnewsnow.com/Articles/292373/STR-US-hotels-postanother-record-year-in-2018

Hu, N., Koh, N. S., \& Reddy, S. K. (2014). Ratings lead you to the product, reviews help you clinch it? The mediating role of online review sentiments on product sales. Decision Support Systems, 57, 42-53. https://doi.org/10.1016/j.dss.2013.07.009

Huber, J. (1997). What we have learned from 20 years of conjoint research: When to use selfexplicated, graded pairs, full profiles or choice experiments. Retrieved June 04, 2020, from https://www.sawtoothsoftware.com/download/techpap/whatlrnd.pdf 
Jalilvand, M. R., Esfahani, S. S., \& Samiei, N. (2011). Electronic word-of-mouth: Challenges and opportunities. Procedia Computer Science, 3, 42-46. https://doi.org/10.1016/j.procs.2010.12.008

Jeong, M., \& Jeon, M. M. (2008). Customer reviews of hotel experiences through consumer generated media (CGM). Journal of Hospitality \& Leisure Marketing, 17(1-2), 121-138.

Kimes, S. E. (2000). Revenue management on the links: Applying yield management to the golf-course industry. Cornell Hotel and Restaurant Administration Quarterly, 41(1), 120-127.

Lee, J., Park, D.-H., \& Han, I. (2008). The effect of negative online consumer reviews on product attitude: An information processing view. Electronic Commerce Research and Applications, 7(3), 341-352. https://doi.org/10.1016/j.elerap.2007.05.004

Lee, S. H. (2016). How hotel managers decide to discount room rates: A conjoint analysis. International Journal of Hospitality Management, 52, 68-77. https://doi.org/10.1016/j.ijhm.2015.09.014

Leong, L. Y., Hew, T. S., Ooi, K. B., \& Lin, B. (2017). Do electronic word-of-mouth and elaboration likelihood model influence hotel booking? Journal of Computer Information Systems, 28(3), 1-15. doi.org/10.1080/08874417.2017.1320953

Litvin, S. W., Goldsmith, R. E., \& Pan, B. (2008). Electronic word-of-mouth in hospitality and tourism management. Tourism Management, 29(3), 458-468. https://doi.org/10.1016/j.tourman.2007.05.011

Lu, W., \& Stepchenkova, S. (2014). User-generated content as a research mode in tourism and hospitality applications: Topics, methods, and software. Journal of Hospitality $\begin{array}{llll}\text { Marketing } & \mathcal{E} & \text { Management } & \text { 24(2), }\end{array}$ https://doi.org/10.1080/19368623.2014.907758

Mariani, M. M., \& Borghi, M. (2018). Effects of the Booking.com rating system: Bringing hotel class into the picture. Tourism Management, 66, 47-52.

Mauri, A. G. \& Minazzi, R. (2013). Web reviews influence on expectations and purchasing intentions of hotel potential customers. International Journal of Hospitality Management, 34, 99-107. https://doi.org/10.1016/j.ijhm.2013.02.012

Millar, M., \& Baloglu, S. (2011). Hotel guests' preferences for green guest room attributes. Cornell Hospitality Quarterly, 52(3), 302-311. https://doi.org/10.1177/1938965511409031

MMGY. (2019). Portrait of American travelers. Retrieved June 04, 2020, from https://www.mmgy.com/services/research-data/portrait-of-american-travelers/

Neirotti, P., Raguseo, E., \& Paolucci, E. (2016). Are customers' reviews creating value in the hospitality industry? Exploring the moderating effects of market positioning. International Journal of Information Management, 36(6), 1133-1143. https://doi.org/10.1016/j.ijinfomgt.2016.02.010

Netzer, O., Toubia, O., Bradlow, E. T., Dahan, E., Evgeniou, T., Feinberg, F. M., et al. (2008). Beyond conjoint analysis: Advances in preference measurement. Marketing Letters, 19(3-4), 337-354. https://doi.org/10.1007/s11002-008-9046-1

Nieto-García, M., Muñoz-Gallego, P. A., \& González-Benito, Ó. (2017). Tourists' willingness to pay for an accommodation: The effect of eWOM and internal reference price. International Journal of Hospitality Management, 62, 67-77. https://doi.org/10.1016/j.ijhm.2016.12.006

Noone, B. M., \& McGuire, K. A. (2013a). Pricing in a social world: The influence of nonprice information on hotel choice. Journal of Revenue \& Pricing Management, 12(5), 385-401. https://doi.org/10.1057/rpm.2013.13 
Noone, B. M., \& McGuire, K. A. (2013b). Effects of price and user-generated content on consumers' prepurchase evaluations of variably priced services. Journal of $\begin{array}{lllll}\text { Hospitality } \& \text { Tourism } & \text { 5esearch, }\end{array}$ https://doi.org/10.1177/1096348012461551

Noone, B. M., McGuire, K. A., \& Rohlfs, K. V. (2011). Social media meets hotel revenue management: Opportunities, issues and unanswered questions. Journal of Revenue and Pricing Management, 10(4), 293-305. https://doi.org/10.1057/rpm.2011.12

Orme, B. (2010). Getting started with conjoint analysis: Strategies for product design and pricing research (2nd ed.). Madison, WI: Research Publishers LLC.

Ögüt, H., \& Taş, B. K. O. (2012). The influence of internet customer reviews on the online sales and prices in hotel industry. The Service Industries Journal, 32(2), 197-214. https://doi.org/10.1080/02642069.2010.529436

Park, C., \& Lee, T. M. (2009). Information direction, website reputation and eWOM effect: A moderating role of product type. Journal of Business Research, 62(1), 61-67. https://doi.org/10.1016/j.jbusres.2007.11.017

Racherla, P., Connolly, D. J., \& Christodoulidou, N. (2013). What determines consumers' ratings of service providers? An exploratory study of online traveler reviews. Journal of Hospitality Marketing \& Management, 22(2), 135-161.

Repetti, T., Roe, S., \& Gregory, A. (2015). Pricing strategies for resort fees: Consumer preferences favor simplicity. International Journal of Contemporary Hospitality Management, 27(5), 790-809. https://doi.org/10.1108/IJCHM-06-2013-0237

Schuckert, M., Liu, X., \& Law, R. (2015). Stars, votes, and badges: How online badges affect hotel reviewers. Journal of Travel \& Tourism Marketing, 33(4), 440-452. https://doi.org/10.1080/10548408.2015.1064056

Sparks, B. A., \& Browning, V. (2011). The impact of online reviews on hotel booking intentions and perception of trust. Tourism Management, 32(6), 1310-1323. https://doi.org/10.1016/j.tourman.2010.12.011

Tanford, S., \& Montgomery, R. (2015). The effects of social influence and cognitive dissonance on travel purchase decisions. Journal of Travel Research, 54(5), 596-610. https://doi.org/10.1177/0047287514528287

Torres, E. N., Adler, H., Lehto, X., Behnke, C., \& Li, M. (2013). One experience and multiple reviews: The case of upscale US hotels. Tourism Review, 68(3), 3-20. https://doi.org/10.1108/TR-03-2013-0012

Torres, E. N., Singh, D., \& Robertson-Ring, A. (2015). Consumer reviews and the creation of booking transaction value: Lessons from the hotel industry. International Journal of Hospitality Management, 50, 77-83. https://doi.org/10.1016/j.ijhm.2015.07.012

Van der Rest, J. P. I., Cordella, P., Loosschilder, G., \& Schwartz, Z. (2016). Connecting search marketing to revenue management: Conjoint analysis as a methodology to evaluate the optimal OTA commission fee. Service Science, 8(2), 1-15. https://doi.org/10.1287/serv.2016.0137

Viglia, G., Minazzi, R., \& Buhalis, D. (2016) The influence of e-word-of-mouth on hotel occupancy rate. International Journal of Contemporary Hospitality Management, 28(9), 2035-2051. https://doi.org/10.1108/IJCHM-05-2015-0238

Westbrook, R. A. (1987). Product/consumption-based affective responses and postpurchase processes. Journal of Marketing Research, 24(3), 258-270.

Wilson, A., Murphy, H., \& Fierro, J. C. (2012). Hospitality and travel the nature and implications of user-generated content. Cornell Hospitality Quarterly, 53(3), 220-228. https://doi.org/10.1177/1938965512449317 
Wong, D. K. K. F., \& Chi-Yung, L. (2002). Predicting hotel choice decisions and segmenting hotel consumers: A comparative assessment of a recent consumer based approach. Journal of Travel \& Tourism Marketing, 11(1), 17-33. https://doi.org/10.1300/J073v11n01_02

Ye, Q., Law, R., \& Gu, B. (2009). The impact of online user reviews on hotel room sales. International Journal of Hospitality Management, 28(1), 180-182. https://doi.org/10.1016/j.ijhm.2008.06.011

Ye, Q., Law, R., Gu, B., \& Chen, W. (2011). The influence of user-generated content on traveler behavior: An empirical investigation on the effects of e-word-of-mouth to hotel online bookings. Computers in Human Behavior, 27(2), 634-639. https://doi.org/10.1016/j.chb.2010.04.014

Zhang, X., Yu, Y., Li, H., \& Lin, Z. (2016). Sentimental interplay between structured and unstructured user-generated contents. Online Information Review, 40(1), 119-145. https://doi.org/10.1108/OIR-04-2015-0101

Zhao, X. (Roy), Wang, L., Guo, X., \& Law, R. (2015). The influence of online reviews to online hotel booking intentions. International Journal of Contemporary Hospitality Management, 27(6), 1343-1364. https://doi.org/10.1108/IJCHM-12-2013-0542 